\title{
Biophysical modeling of larval Baltic cod (Gadus morhua) growth and survival
}

\author{
H.-H. Hinrichsen, C. Möllmann, R. Voss, F.W. Köster, and G. Kornilovs
}

\begin{abstract}
A coupled hydrodynamic-trophodynamic individual-based model of drift and feeding was utilized to analyze the intra- and inter-annual variability in growth and survival of cod (Gadus morhua) larvae in the central Baltic Sea. Highly temporally and spatially resolved simulated flow fields were used to investigate the potential drift of larval cod from the centre of spawning effort in the Bornholm Basin towards their nursery areas through temporally resolved three-dimensional idealized prey fields. Stomach content analyses of larval cod from the Bornholm Basin revealed calanoid copepod nauplii and early copepodite stages to be the preferred prey organisms. The results of the model runs indicate that larval cod changed from a nonlimited to a food-limited stage because of the strong decrease in abundance of the calanoid copepod Pseudocalanus elongatus during the last two decades. The modeling study revealed retention and dispersal from the main spawning ground to be a key process influencing larval survival. When P. elongatus was available in the prey fields, high cod larval survival rates occurred in spring and early summer. In contrast, when P. elongatus was not available, hatched larvae had only high survival probabilities later in the year or if they were transported into shallower coastal regions.
\end{abstract}

Résumé : Un modèle couplé hydrodynamique-trophodynamique basé sur l'individu qui décrit la dérive et l'alimentation nous a permis d'analyser la variabilité intra- et inter-annuelle de la croissance et de la survie des larves de la morue franche (Gadus morhua) dans le centre de la Baltique. Des champs à hautes résolutions temporelle et spatiale d'écoulement simulé ont servi à étudier la dérive potentielle des larves de morue à partir du point central où se produit l'effort maximal de fraie dans le bassin de Bornholm vers les zones de nourricerie à travers des champs idéalisés à trois dimensions et à haute résolution de prédateurs. L'analyse des contenus stomacaux des larves de morue du bassin de Bornholm révèle que les nauplies de copépodes calanoïdes et les premiers stades copépodites sont les proies préférées. À cause de l'important déclin de l'abondance du copépode calanoïde Pseudocalanus elongatus au cours des deux dernières décennies, les résultats de la modélisation indiquent que les larves de morue sont limitées par une pénurie de nourriture, alors qu'elles ne l'étaient pas auparavant. Le modèle démontre que la rétention et la dispersion à partir du site principal de fraie sont les processus déterminants qui influencent la survie des larves. Quand P. elongatus est disponible dans les champs de proies, les taux de survie des larves de morue au printemps et au début de l'été sont élevés. En revanche, lorsque P. elongatus n'est pas disponible, les larves à l'éclosion n'ont de fortes probabilités de survie que plus tard dans l'année et seulement si elles sont transportées vers les régions côtières moins profondes.

[Traduit par la Rédaction]

\section{Introduction}

Studies of recruitment processes have often focused on correlations among environmental factors, stock characteristics, and recruitment levels or, alternatively, on single processes occurring at the level of individual organisms or single life stages, for example, mortality or starvation (e.g., Werner et al. 1993; Letcher et al. 1996). It is now generally accepted that a variety of mechanisms operating on different temporal and spatial scales may be important and that overall recruit-

Received 4 October 2001. Accepted 30 September 2002.

Published on the NRC Research Press Web site at

http://cjfas.nrc.ca on 3 January 2003.

J16559

H.-H. Hinrichsen, ${ }^{1}$ C. Möllmann, R. Voss, and F.W.

Köster. Institute of Marine Sciences, Düsternbrooker Weg 20, D-24105 Kiel, Germany.

G. Kornilovs. Latvian Fisheries Research Institute,

Daugavgrivas Street 8, LV-1007 Riga, Latvia.

${ }^{1}$ Corresponding author (e-mail: hhinrichsen@ifm.uni-kiel.de). ment levels are unlikely to be controlled by a single factor, process, or life stage (e.g., Rothschild 2000).

Variability in growth and mortality is known to cause fluctuations in fish stock recruitment (Houde 1989; Pepin and Myers 1991). Mortality during pelagic larval and juvenile stages is especially believed to be a critical mechanism influencing recruitment success. This mortality may be episodic, removing large numbers over short periods as the result of specific events such as mass starvation or unfavourable drift into suboptimal feeding environments, or may remove a small percentage of the population daily as the result of predation or starvation. The growth and mortality of marine fish larvae depend on body size, food availability, temperature, and predation (e.g., Houde and Zastrow 1993; Otterlei et al. 1999). Other studies emphasize the importance of advection into or out of areas with optimal environmental feeding conditions resulting in variations in recruitment success (e.g., Werner et al. 1993).

Recent efforts to understand the causes of mortality and survival of larval fish have focused on examining the effects of advective and trophodynamic (feeding and growth) pro- 
cesses (e.g., Werner et al. 1993; Letcher et al. 1996). Trophodynamic relationships are generally based on the contact rates between predator and prey, usually estimated from the relative density or changes in the relative density of predator and prey. Theoretical work suggests that small-scale turbulence enhances encounter rates between larval fish and their prey (Rothschild and Osborn 1988) and additionally influences the probability of successful pursuit and ingestion of prey (Dower et al. 1997). However, turbulence can have either an overall beneficial or detrimental effect on larval fish ingestion rate depending on the turbulence and on larval behaviour (MacKenzie et al. 1994).

The stock development of central Baltic cod (Gadus morhua) size has been characterized by a pronounced decline since the beginning of the 1980s. Identified reasons were a combination of recruitment failure and concurrent overfishing (Bagge et al. 1994). The relevance of mesoscale ocean processes in the Baltic Sea (Fig. 1) and the climatic conditions driving them has been increasingly in focus for explaining recruitment variability of central Baltic cod (e.g., Hinrichsen et al. 2001; Köster et al. 2001). Furthermore, ocean processes influence the physical environment conducive for successful egg development (Hinrichsen et al. 2002) as well as the feeding environment (Möllmann et al. 2000) of early life history stages.

For Baltic cod, the main larval feeding components consist of juvenile calanoid copepod stages (Pseudocalanus elongatus, Acartia spp., Temora longicornis, Centropages hamatus) and cladoceran species (Bosmina longispina maritima, Evadne nordmanni, Podon spp.; Zuzarte et al. 1996). The long-term biomass development of copepods in the Baltic is characterized by a decline in standing stock of the dominant copepod P. elongatus, especially in the late 1980s and early 1990s. In parallel, the other copepod species exhibited in general positive biomass developments, which is especially true for Acartia spp. These trends have been explained by variations in the hydrographic environment, for example, salinity and temperature (Möllmann et al. 2000), ultimately controlled by climatic forcing (Dippner et al. 2000; Hänninen et al. 2000).

The coupling of a circulation model with trophodynamic relationships of larval fish can be utilized to examine starvation mortality and growth rates at the level of individual larvae as well as estimating larval losses from the system (e.g., Rose et al. 1993; Hinckley et al. 2001). We developed a coupled hydrodynamic-trophodynamic individual-based model (IBM) of drift and feeding designed to examine growth and survival of Baltic larval cod. This coupled model allows an examination of feeding success, growth, and starvation mortality of larval cod in the presently most important spawning area (Köster et al. 2001), the Bornholm Basin (Fig. 1), in the context of their transports by utilizing trophodynamic relationships along their potential drift routes. Implementation of the coupled model required zooplankton abundance as well as turbulence and temperature fields as inputs to the larval feeding, metabolic, and growth components. At present, utilization of this model allows a general examination of how habitat and environment affect survival and growth variability, however, with potential for improvement in the biological model components. The present model does not include predation on larval cod, as it is apparently only of minor importance for larval survival mainly because of a limited vertical overlap between predator and prey (Köster and Schnack 1994; Köster and Möllmann 1997).

The main purposes of this modeling exercise were $(i)$ to characterize temperature- and size-dependent growth of Baltic cod larvae and (ii) to identify seasonal, interannual, and spatial variability in larval survival. The sensitivity of growth and survival was studied by modeling the fate of larvae for various scenarios in prey fields as well as by considering the seasonal effect and spatial differences of temperature. For example, the impact of the observed declining standing stock of the main prey component of larval cod in the Baltic Sea, the calanoid copepod $P$. elongatus, was simulated by using prey fields with and without this copepod species, considering as well its intraannual temporal and spatial variability. Validation of the simulated larval survival potential has been performed by instead considering egg production data at a late stage close to larval hatch. Furthermore, to test for the sensitivity and applicability of the coupled model to assess temporal and spatial differences in larval survival, we present a sensitivity analysis of the larval bioenergetics models by examining the implications of parameter variation on larval survival as well as a correlation analysis of larval prey availability and recruitment of Baltic cod during the last three decades.

\section{Methods}

\section{Model description and design of simulations}

We have combined a three-dimensional eddy-resolving hydrodynamic model of the Baltic Sea (Lehmann 1995) with an IBM for larval cod. This IBM tracks individuals through the larval phase distinguishing four stages: yolk-sac larvae $(<4.5 \mathrm{~mm})$, first-feeding larvae $(4.5-6 \mathrm{~mm})$, well established feeding larvae $(6-9 \mathrm{~mm})$, and large larvae $(>9 \mathrm{~mm})$. Within the model, the encounter of prey, foraging, growth, and survival of individual cod larvae is simulated by specific submodels in 6-h time steps. All larvae were initially defined to have equal length and weight at hatch. Along the drift trajectories within the coupled model, the larval environment consisted of the prey field, ambient temperature, and turbulence determining both their growth and survival. Yolk-sac larvae before reaching length-at-first-feeding $(<4.5 \mathrm{~mm})$ were considered passive drift particles, with growth exclusively determined by ambient temperature. To analyze the survival and growth of larval Baltic cod, the following simulation output variables were obtained by using the coupled model: $(i)$ survival dependent on minimum weight growth rates, (ii) days of starvation (when the amount of food ingested does not cover metabolic costs), (iii) condition of larvae (weight) at $6 \mathrm{~mm}$ length, and (iv) growth in terms of mean length after 70 days of drift and feeding.

\section{Hydrodynamic model}

The hydrodynamic model is based on the free-surface Bryan-Cox-Semtner model (Killworth et al. 1991), which is a special version of the Cox numerical ocean general circulation model (Bryan 1969; Semtner 1974; Cox 1984). A detailed description of the equations and modifications made, necessary to adapt the model to the Baltic Sea, can be found in Lehmann (1995) and Lehmann and Hinrichsen (2000). The model domain consists of the entire Baltic Sea. The 
Fig. 1. Map of the Baltic Sea, including Bornholm Basin, the area of investigation.

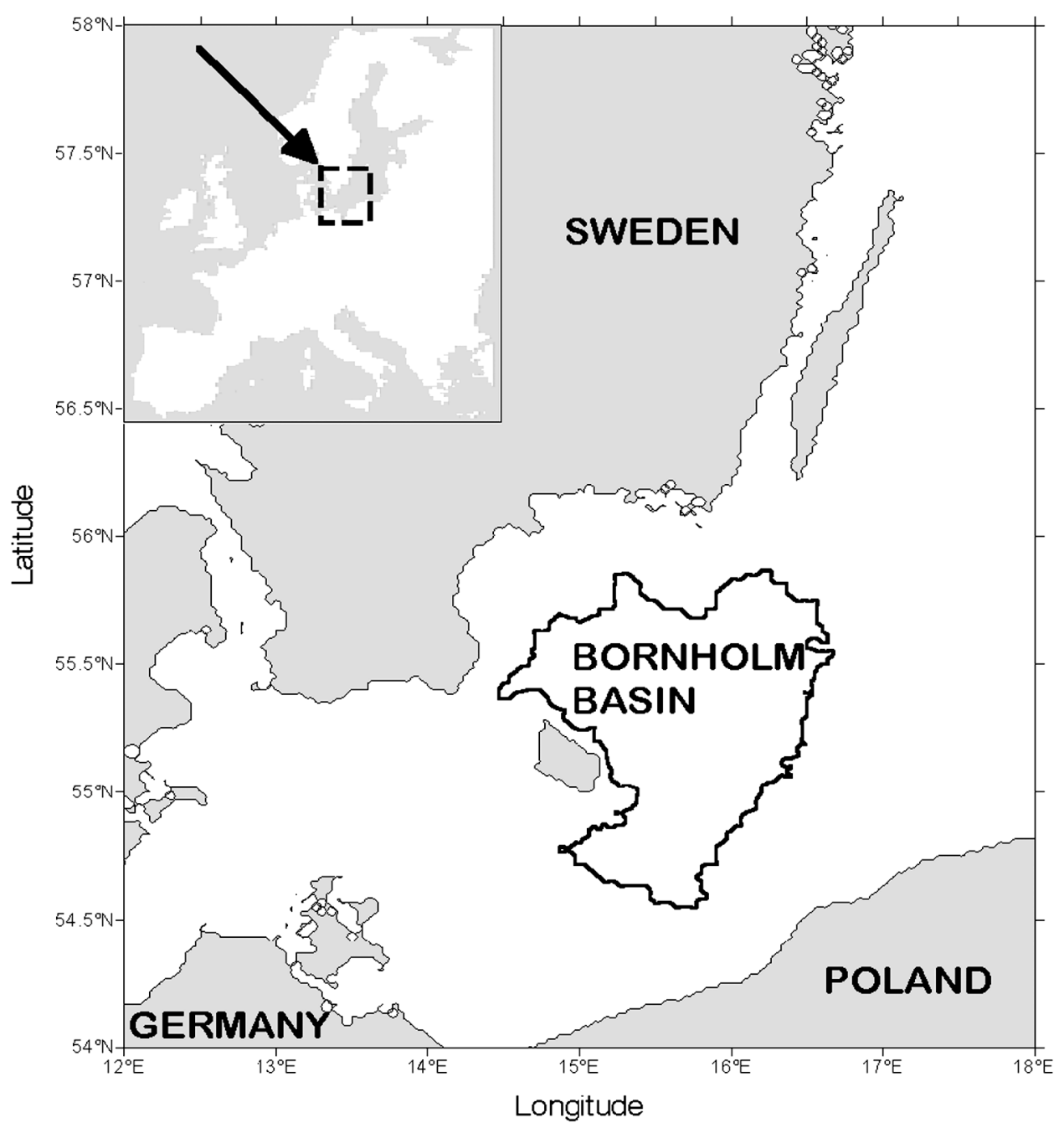

horizontal resolution is $5 \mathrm{~km}$, with 41 vertical levels specified. The thickness of the different levels is chosen to best account for the different sill depths in the Baltic. Fennel (1991) determined the internal Rossby radius to be in the range of $2-10 \mathrm{~km}$ for the Baltic. A horizontal resolution in the order of the half internal Rossby radius (at least in the order of the Rossby radius) is required to resolve the whole spectrum of mesoscale motions. Simulated three-dimensional velocity fields were extracted to develop a database for a Lagrangian particle tracking exercise on larval cod. This data set offers the possibility to derive Lagrangian drift routes by calculating the advection of "marked" water particles representing individual larvae. Vertical velocities were calculated from the divergence of the horizontal velocity fields. Three-dimensional trajectories of the simulated drifters were computed using a 4th-order Runge-Kutta scheme (Press et al. 1993). The drifters were allowed to leave the layers from which they were initially released. The positions of the drifters varied over time as a result of the three-dimensional velocities that they experienced. Furthermore, the data contain information on the temporal evolution of the hydrographic property fields (temperature, salinity, oxygen, current velocity, etc.) along the trajectories. The initial launch positions can be chosen independently from the vertical resolution of the model's grid.

\section{Trophodynamic IBM}

Encounter and turbulence submodels

Encounter rates of larval fish with their prey are functions of both larval fish size $(l)$ and prey size and density (Blaxter 1986). The number of prey items $N(l, i)(i=1, \ldots, n)$ encountered depends on the search volume (SV) in which larvae perceive prey and its concentration $p(i)$ (ith prey $\left.\cdot \mathrm{L}^{-1}\right)$. Cod larvae are visual predators (Last 1978) and their main daily feeding period can be described as the fraction of daylight hours $H$ (Morse 1989; Voss 2002):

$$
N(l, i)=\mathrm{SV}(l, i) p(i) H
$$

The search volume was defined as the product of the fish swimming speed $\mathrm{SS}(l)$ and the area that a fish of length $l$ can scan for food (RA):

$$
\operatorname{SV}(l, i)=\operatorname{SS}(l) \operatorname{RA}(l, i)
$$

For swimming speeds of larvae, we used the summary relationship of Miller et al. (1988). This equation yields swim- 
ming speeds of $\sim 1$ body length $\cdot \mathrm{s}^{-1}$. This relationship implicitly assumes a cruising and not a pause-travel predator, although indications exist that cod larvae belong to the latter group (MacKenzie and Kiørboe 1996). However, given the relatively low, on average, prey concentrations encountered by larvae in the Baltic (compared with, for example, Georges Bank; Werner et al. 1993), we assumed larvae to have spent most of their time cruising when searching for prey. The reactive area $\left(\mathrm{RA}, \mathrm{mm}^{2}\right)$ was assumed to be half a circle with a radius equal to the reactive distance (RD) and was defined for each prey type $i$ as

$$
\mathrm{RA}(l, i)=0.5 \pi \mathrm{RD}(l, i)^{2}
$$

The search volumes (SV) increase rapidly with increases in larval size and prey size. Prey sizes have been taken from Hernroth (1985). RD (mm) was defined as a function of both prey body length and larval length using the relationship of Breck and Gitter (1983).

Including turbulence in the calculation for prey encounter rates (Rothschild and Osborn 1988) results in the number of $i$ th prey encountered estimated as

$$
N(l, i)=H A(l, i) D(l, i)
$$

instead of eq. 1 . The effect of turbulent velocities enters into the determination of $A(l, i)$ as the velocity of larval fish relative to its prey and to turbulent motions (Rothschild and Osborn 1988). $D(l, i)$ is the product of the cross-sectional area of perception of the larvae RA and the prey concentration $p(i)$. Turbulent velocities required for the determination of $A(l, i)$ can be obtained by different methods. The simplified relationship utilized enables the calculation of turbulent velocities (MacKenzie et al. 1994) directly dependent on the cube of wind speed and larval depth. Wind speed and direction were obtained from the weather station Christians $\varnothing$ (an island northeast of Bornholm), as well as from atmospheric data provided by the Swedish Meteorological and Hydrological Institute (SMHI, Norrköping, Sweden).

\section{Foraging submodel}

Larval fish typically are not able to attack all prey encountered, thus time required for feeding reduces search time. To simulate this process, we utilized a submodel characterizing optimal foraging dependent on the swallowing probability (SP) determined empirically for cod and haddock larvae by Laurence (1985). This rather simple approach is dependent on both the initial dry weight-at-hatch $\left(w_{\min }\right)$ and weight-atage $(w)$ :

$$
\mathrm{SP}=0.9\left\lfloor 1-0.667 \mathrm{e}^{-0.004\left(w-w_{\min }\right)}\right\rfloor
$$

\section{Growth submodel}

Temperature influences metabolic processes and is the most important factor, besides prey availability, that determines growth in fish (Brett 1979). As obtained from rearing experiments with Norwegian coastal cod (Otterlei et al. 1999), somatic growth increased with increasing temperature for sufficient food supply. Following the approach by Otterlei et al. (1999) to model weight-specific growth rates in dependence of temperature, we have calculated length-specific average growth rates for Baltic cod from five cruises conducted in the late 1980s and early 1990s. In the procedure, we computed average length growth rates from established cruise-specific age-length relationships and related them to the average ambient temperature derived from vertically resolving net sampling and concurrent hydrographic measurements. This resulted in a nonlinear relationship between age and length. Thus, if larvae experience food levels that are not superabundant, then higher survival could be the result of lower temperature yielding lower specific larval growth rates. On the other hand, although food availability is higher, survival could be lower if larvae encounter higher ambient temperature.

Larval growth is simulated by the standard bioenergetic supply-demand function, represented as the difference between the amount of food ingested by a larva and the metabolic costs of its activities. The daily growth increment

$$
G=\mathrm{AE} g-m
$$

is the difference between the total food input $(g)$ times the assimilation efficiency (AE) and the loss resulting from the weight-dependent metabolic costs $(m)$ (Werner et al. 1996). Starvation obviously occurred if the metabolic costs were higher than the weight gained from feeding. The assimilation efficiency

$$
\mathrm{AE}=0.8\left(1-0.25 \mathrm{e}^{-0.002(w-10)}\right)
$$

is the proportion of ingested food not egested by the larvae (Buckley and Dillmann 1982). The assimilation efficiency strongly depends on the larval mass $(w)$ ranging from 0.6 to 0.8 increasing rapidly with larval size. The ingested food provides energy exclusively used for growth after accounting for the energy from metabolic costs. To prevent unlimited growth of larvae at superabundant food levels, larval growth is limited to maximum values calculated from the lengthweight relationship as obtained from rearing experiments under food saturation performed by Otterlei et al. (1999).

\section{Starvation submodel}

Length-weight relationships from Otterlei et al. (1999) were applied to compute the expected weight under superabundant prey concentrations. Deviation of the simulated weight from the bioenergetics model and this maximum weight-at-length $\left(W_{\max }\right)$ were utilized to run the starvation model. Larvae were defined to die from starvation if the final weight in a specific stage $\left(W_{\min }\right)$ was falling below a threshold value $(a)$ times the maximum weight

$$
W_{\min }=a W_{\max }
$$

The threshold was set to 0.75 (Letcher et al. 1996). This submodel also allowed determination of larval condition, i.e., weight-at-length, at death from starvation.

\section{Prey fields}

Zuzarte et al. (1996) revealed copepod nauplii and early copepod stages to be the preferred prey of larval cod from the Bornholm Basin. This is similar to what has been observed for other cod stocks (Wiborg 1948). Additionally, cladocerans contributed in small numbers to the diet of larval Baltic cod (Zuzarte et al. 1996). These results are based on larval cod gut content data determined from a total of 1324 larvae sampled of which 1000 had food particles ingested from 10 cruises conducted during the period April- 
September 1987 and 1988. Utilizing the same data set, R. Voss, F.W. Köster, and M. Dickmann (unpublished data) studied the size dependency of larval diets. Prey numbers found in the diet were converted to wet weight using the formula given by Hernroth (1985). Small larvae (4-6 mm length) depend almost exclusively on nauplii (93\% in wet weight) as food source. In the length class 6-9 $\mathrm{mm}$, copepodite stages I-V gain importance (16\% compared with $75 \%$ nauplii). Larger larvae $(>9 \mathrm{~mm})$ additionally feed on adult copepods and cladocerans $(25 \%$ wet weight compared with $49 \%$ copepodites). For the present modeling approach, we specified the potential food organisms-stages for feeding larvae accordingly: first-feeding larvae $(4.5-6.0 \mathrm{~mm})$, which exclusively feed on nauplii of calanoid copepods (95\% coefficient of variation (CV) of prey size $0.17-0.33 \mathrm{~mm}$ ), and larvae of length between 6 and $9 \mathrm{~mm}$, which also feed on copepodite stages of calanoid copepods $(95 \% \mathrm{CV}$ of prey size $0.12-0.42 \mathrm{~mm}$ ) in addition to nauplii. Larvae $>9 \mathrm{~mm}$ were found to be able to ingest all life stages of calanoid copepods as well as cladocerans $(95 \% \mathrm{CV}$ of prey size $0.11-$ $0.64 \mathrm{~mm})$.

Zooplankton abundance data for the central Baltic Sea were derived from an extensive database compiled by the Latvian Fisheries Research Institute in Riga within the European Union funded project "Baltic Sea System Study (BASYS)". Mesozooplankton abundance were sampled with a Juday net (UNESCO Press 1968) operated vertically with a mesh size of $160 \mu \mathrm{m}$ and an opening diameter of $0.36 \mathrm{~m}$. Individual hauls were carried out to a maximum of $100 \mathrm{~m}$ deep. Sampling was performed on various stations in variable steps from $0-25,25-50$, and $50-100 \mathrm{~m}$. In case of higher vertical resolution, abundance values were averaged to meet the two shallow water layers corresponding to the depths in which feeding cod larvae occur (Grønkjær and Wieland 1997). For detailed descriptions of the database as well as sampling and analysis procedures, see Dippner et al. (2000) and Möllmann et al. (2000). We included in the prey fields the dominant calanoid copepod (P. elongatus, Acartia spp., T. longicornis, $C$. hamatus) and cladoceran species (B. longispina maritima, E. nordmanni, Podon spp.) (Möllmann et al. 2000). Densities of copepod nauplii, copepodites, and adults as well as cladocerans were combined to represent prey fields for above-larval size classes assigned to bottom depth and day of the year.

To obtain a spatiotemporal resolution of prey, the zooplankton abundances from all stations covered in the central Baltic, i.e., originating from the Bornholm and the Gotland Basin as well as the Gdansk Deep, were fitted to a secondorder polynomial function:

$$
F_{(d, t)}=\sum_{i=1}^{N} \sum_{j=1}^{N} p_{i j} d^{(i-1)} t^{(j-1)}
$$

which is determined by a multiple regression analysis using the least-square criteria. $p_{i j}$ is the abundance of the above-described size-specific food organisms; $d$ represents the bottom depth at any location and time $t$ is given in Julian days. Highly significant relationships were established $(P<0.001)$, however, explaining only between 10 and $15 \%$ of the variance.

\section{Model simulations}

First, coupled hydrodynamic-trophodynamic IBM runs were performed for the spawning periods of 1986 to 1999 to ob- tain the average intra-annual variability in survival and growth. Therefore, a total of 720 Lagrangian drifters were released at depths between 25 and $35 \mathrm{~m}$ on a three-dimensional regularly spaced grid enclosed by the $60-\mathrm{m}$ isobath, the area where peak egg and larval abundances were observed regularly (Wieland 1995). The drifters were released into the modeled flow fields at 10-day intervals and were tracked for a period of 70 days. This time period approximately covers the duration of the larval phase of cod (Fossum 1986). The first release date was 1 April and the last was 20 September, thereby encompassing the main spawning period of central Baltic cod (MacKenzie et al. 1996; Wieland et al. 2000). To investigate the effect of the strong decay in P. elongatus abundance, simulations were performed with mean prey fields excluding and including this species. No effect of turbulence on the feeding of cod larvae was implemented in these simulations.

We next simulated the interannual variability in survival and growth of larvae originating from peak spawning times of years 1986-1999. Dates of peak spawning were estimated by Wieland et al. (2000) based on ichthyoplankton survey results. Model simulations were initialized by ignoring turbulence and using prey fields without $P$. elongatus. In the following we successively modified the simulations by taking into account $(i)$ the effect of turbulence on contact rates between predator and prey, (ii) the interannual trend in prey availability by multiplying mean nauplii abundance by its year-specific weights (Table 1) estimated from annual nauplii biomass estimates including $P$. elongatus (Möllmann et al. 2000), and (iii) the vertical distribution of the zooplankton prey. As obtained from field investigations (Grønkjær and Wieland 1997), the vertical distribution of the smallsized zooplankton particles was twofold higher in the upper part of the intermediate layer $(25-37.5 \mathrm{~m})$, where Baltic cod larvae preferably dwell, compared with the lower part (37.5$50 \mathrm{~m}$ ). Finally, we investigated the spatial distribution of hatching first-feeding larvae surviving during simulations with prey fields excluding and including $P$. elongatus.

\section{Validation of the biophysical model}

First, sensitivity analyses have been performed for all submodels to examine the implications of parameter uncertainty on larval survival. We have used individual parameter perturbations (Bartell et al. 1986) to assess larval survival with respect to each parameter. Single-parameter values were decreased and increased by three levels of variation $(5,10$, and $25 \%$ ), whereas remaining parameters remained fixed at initial values. A measure for the quality of the results is how the uncertainty in the description of the parameter fields translates into deviations of larval survival compared with reference values obtained by the original runs.

Secondly, as the major validation step of the coupled biophysical model results, recruits of Baltic cod at age 2 obtained from virtual population analyses (VPA; ICES 2001) in relation to egg production at stage III (Köster et al. 2001) were compared with the corresponding simulated larval survival potential. For Baltic cod, egg production at this late stage was considered to be representative for the early larval (hatch) stage. The simulated larval survival potential was available for the time period from 1986 to 1997 (no data for 1992). 
Table 1. Annual weighting factors for nauplii abundances derived from biomass estimates in the central Baltic Sea 1986-1997 (1992: no data).

\begin{tabular}{|c|c|c|c|c|c|c|c|c|c|c|c|}
\hline & 1986 & 1987 & 1988 & 1989 & 1990 & 1991 & 1993 & 1994 & 1995 & 1996 & 1997 \\
\hline Weighting factor & 0.95 & 1.03 & 0.55 & 0.70 & 0.87 & 1.33 & 0.23 & 0.29 & 0.24 & 0.45 & 0.36 \\
\hline
\end{tabular}

In a final step, as an independent test of the validity of the model, results have been evaluated by simply relating recruitment success of Baltic cod to the availability of P. elongatus nauplii as prey. Recruits at age 2 were taken from VPA on an annual basis for the time period 1966 to 1998. Food availability was defined as the product of quarterly averaged abundances (Möllmann et al. 2000) and temperaturedependent nauplii development times (Davis 1984). To assess the dependency of residual recruitment variability on larval food availability, long-term trends were removed from both original time series by utilizing a 3rd-order functional relationship.

\section{Results}

All simulations revealed optimal feeding conditions for cod larvae $>6 \mathrm{~mm}$. These larvae feed on copepod nauplii, copepodite stages, and at larval length $>9 \mathrm{~mm}$ also on adult copepods and cladocerans. The specified prey distribution and abundance was sufficient for survival and growth of these larvae. On the contrary, for larvae between 4.5 and $6 \mathrm{~mm}$ long exclusively feeding on copepod nauplii, pronounced differences in growth and survival were observed that depend on food availability as well as on ambient temperature.

\section{Constructed nauplii prey fields encountered by larvae of $4.5-6 \mathrm{~mm}$}

The two-dimensional (bottom depth and time-dependent) distribution of copepod nauplii including $P$. elongatus revealed a pronounced seasonal signature (Fig. 2). Peak nauplii abundance of about 3000 nauplii. $\mathrm{m}^{-3}$ was observed in the upper layer $(0-25 \mathrm{~m})$. Highest concentrations were found mainly in the deeper part of the basin with mean peak nauplii abundances between Julian day 100 and 150. In shallower coastal areas, peak abundance lagged 50 days behind. The lower layer $(25-50 \mathrm{~m})$ exhibited similar conditions as the nearsurface layer with the same time period of peak nauplii abundance but overall lower concentrations $\quad(\sim 1100$ nauplii $\left.\cdot \mathrm{m}^{-3}\right)$.

Mean prey fields, including Acartia spp., T. longicornis, and $C$. hamatus only, showed maximum abundance within coastal regions for both depth layers (Fig. 2). Compared with prey fields including $P$. elongatus, the concentrations were about twofold lower, with maximum abundances occurring later in the year (around Julian day 300). During the period of peak abundance, coastal areas revealed twice the concentration observed for the deep part of the basin.

\section{Intra-annual variability}

Firstly, we simulated the intra-annual variability in survival and growth of larvae between 4.5 and $6 \mathrm{~mm}$ experiencing prey fields described above with and without $P$. elongatus. Model output parameters, as well as ambient environmental variables of surviving larvae during the
Fig. 2. Constructed mean prey fields of time and bottom depth dependent nauplii distribution (a) including Pseudocalanus elongatus 0-25 m, $(b)$ including $P$. elongatus $25-50 \mathrm{~m}$, and (c) excluding $P$. elongatus $0-25 \mathrm{~m}$, and $(d)$ excluding P. elongatus $25-50 \mathrm{~m}$.
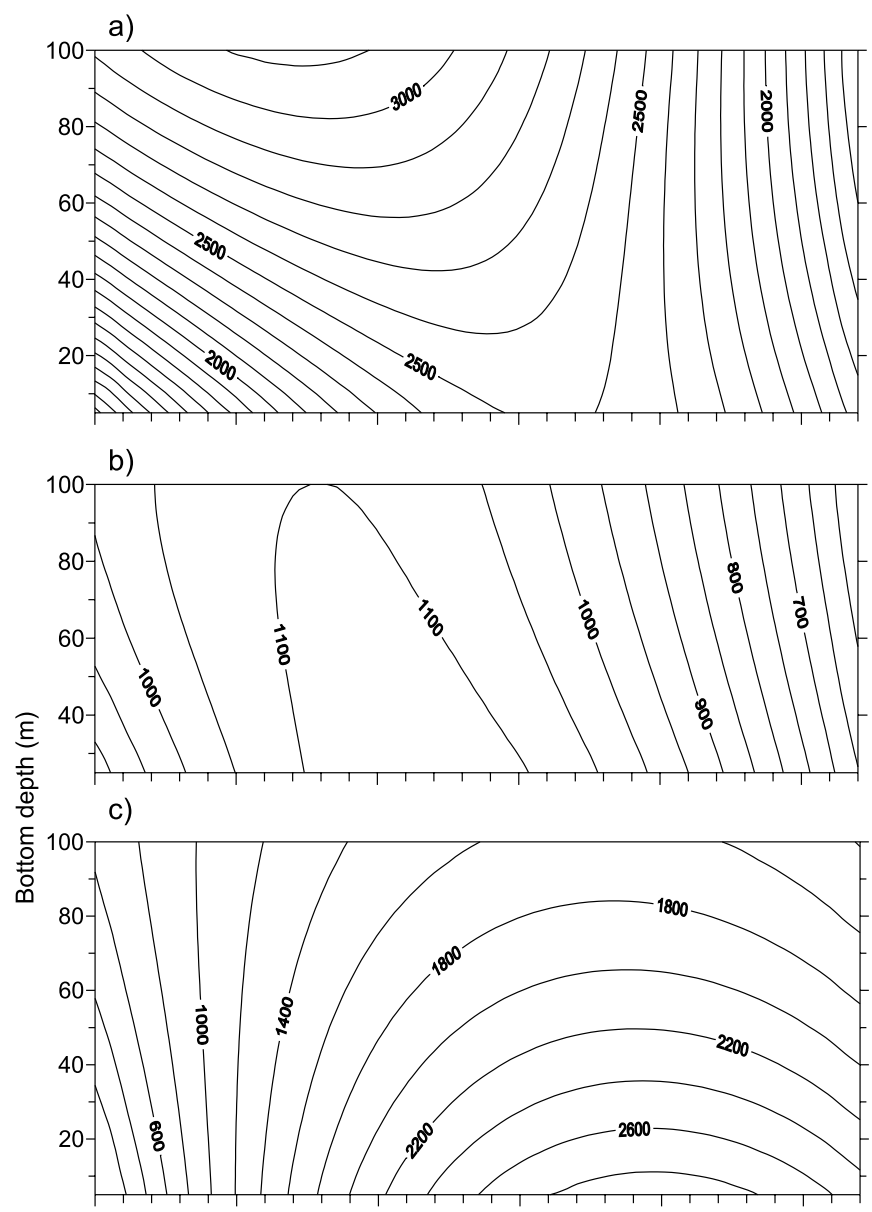

d)

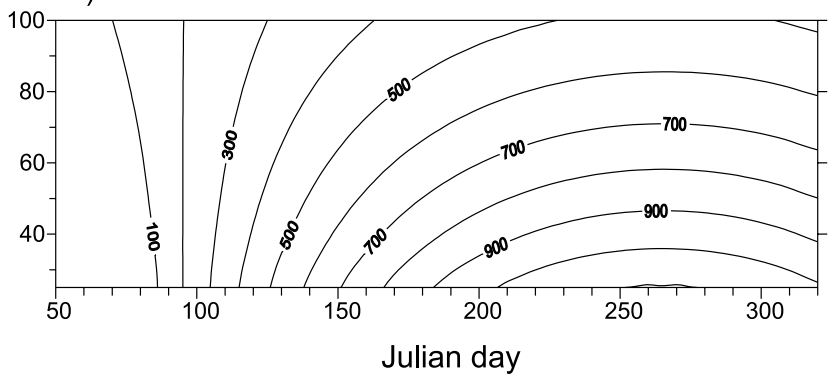

spawning period of Baltic cod, were averaged over the whole observational period of years 1986-1999 (see Figs. 3a, 3b). The $x$ axis represents the day of larval release (Julian day). Note that the whole set of parameters exclusively describes the state of the surviving proportion of the initially simulated population. 
Fig. 3. (a) Averaged (1986-1999) seasonal model output parameters of surviving larvae obtained from simulations with (shaded bars) and without (solid bars) Pseudocalanus elongatus: survival rate, starvation periods, mean weight at 6 mm length, length after 70 days of drift and feeding, and the development time until the end of the first-feeding stage. (b) Averaged (1986-1999) seasonal ambient environmental variables of surviving larvae obtained from simulations with (shaded bars) and without (solid bars) P. elongatus: ambient temperature, bottom depth, larval depth, and nauplii abundance.

a)
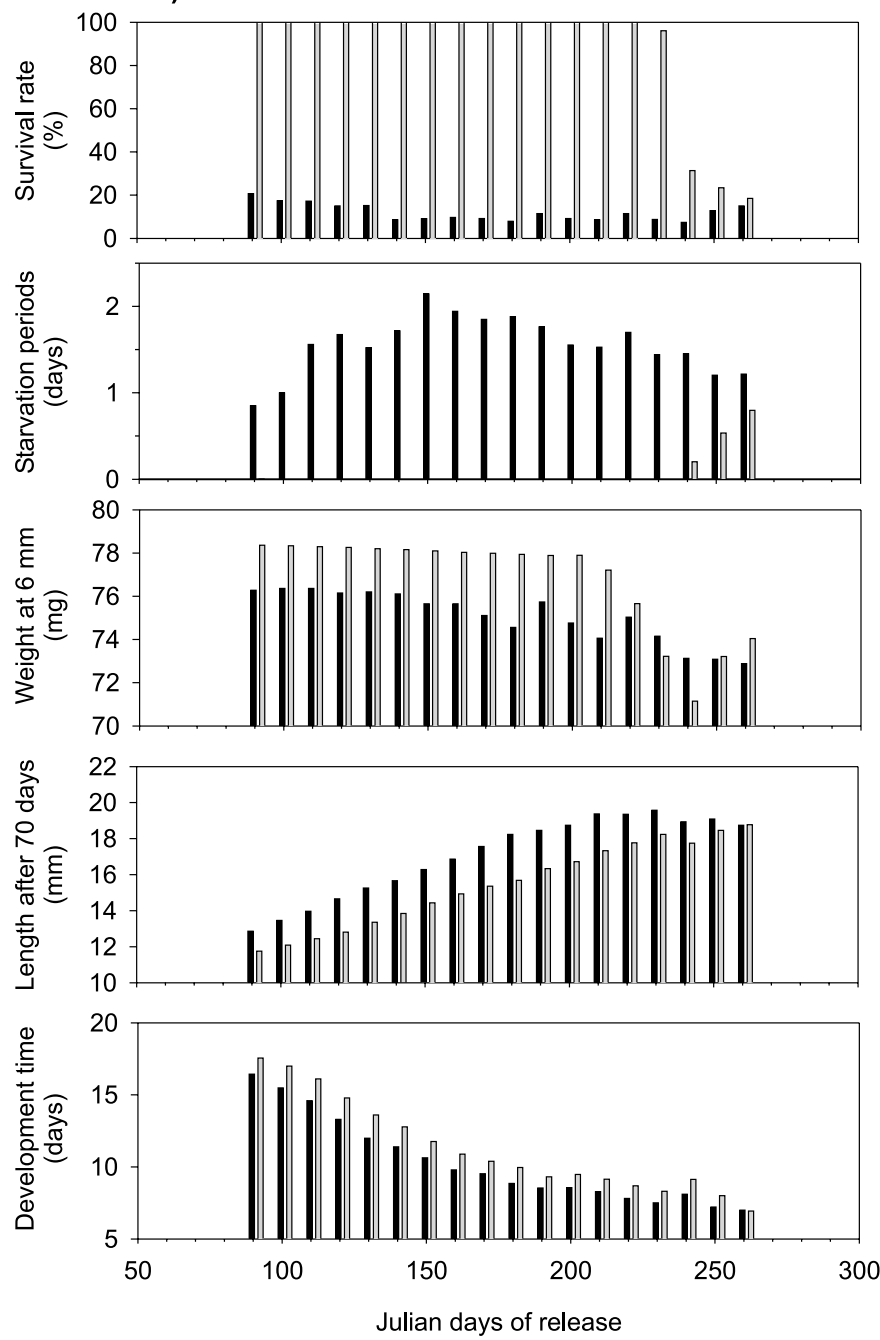

The survival rate of larvae experiencing prey fields without $P$. elongatus seldom exceeded $15 \%$ except during periods in early spring and at the end of the spawning season when environmental conditions enabled between 15 and $20 \%$ of the initially hatched larvae to survive. Consequently, an opposite trend in starvation periods was observed within a range of 0.5-2 days. Higher survival in spring was a result of lower ambient temperatures yielding lower specific larval growth rates (Otterlei et al. 1999). Thus a lower amount of food is required, allowing relatively high survival with low nauplii abundance. In contrast, survival was lower in summer, although the available amount of food was higher. This was due to higher ambient temperatures encountered by the larvae resulting in shorter development times and high prey availability needed for this rapid development. Consequently, the number of starvation days was high in early summer when drift into coastal areas with enhanced prey abundance was also less frequent (not shown) compared with the beginning of the spawning period when temperature was b)

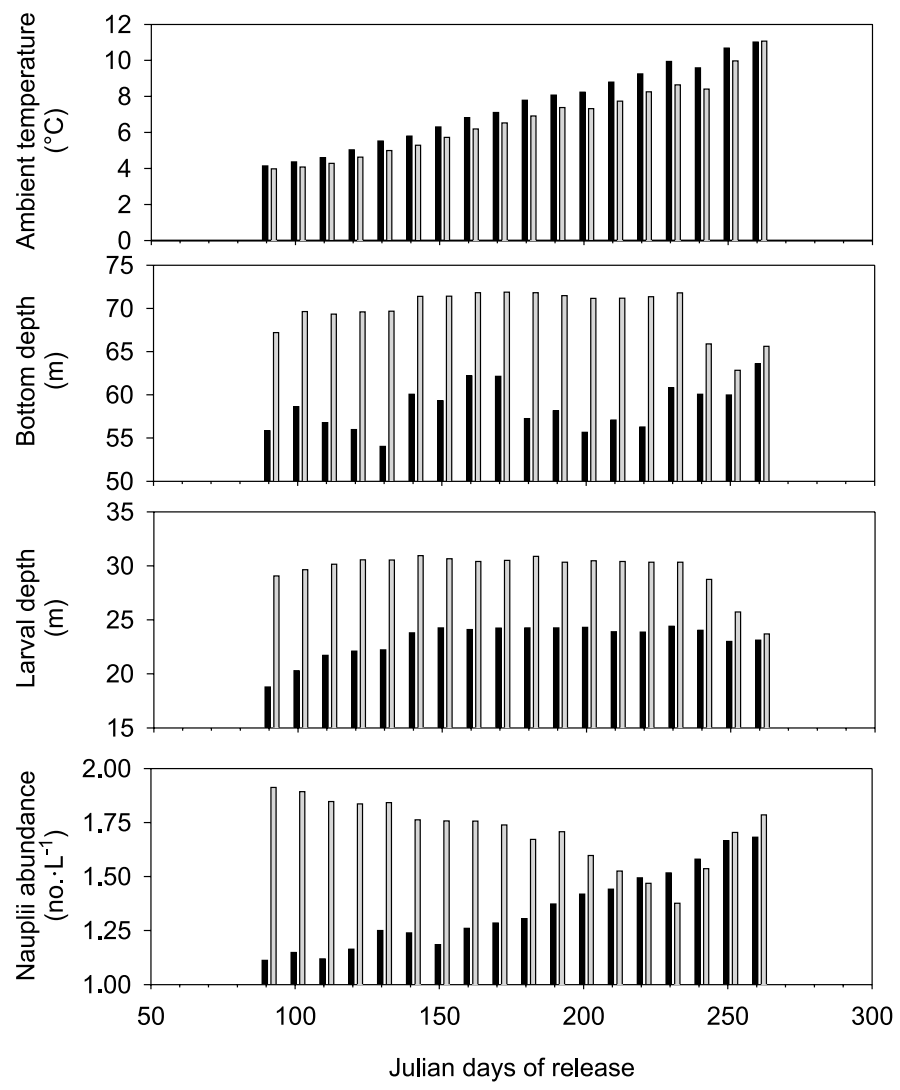

lower. The mean larval condition expressed as the weight at $6 \mathrm{~mm}$ length was also high in spring, reflecting favourable environmental conditions. Finally, larval growth expressed as length-at-age of 70 days was found to be mainly driven by ambient temperatures. At the beginning of the spawning period, low growth rates and hence lower demands of food needed resulted in smaller individuals at age, but nevertheless the larvae reached their length of metamorphosis $(12 \mathrm{~mm})$. Because of the seasonal warming, growth accelerated towards summer months and early juvenile length after 70 days reached maximum values $(18-20 \mathrm{~mm})$ between Julian day 200 and 260. Consequently, the average duration of the larval stage decreased throughout the season.

To evaluate the importance of $P$. elongatus for growth and survival of Baltic cod larvae, nauplii of this copepod species were added to the mean prey fields. Survival rates were $100 \%$, except for drift and feeding periods at the end of the main spawning time, i.e., releases between Julian days 231 and 261. This decreased survival at the end of the season 
was accompanied by an increase in days of starvation and resulted in worse larval conditions, expressed by their low weight at $6 \mathrm{~mm}$. This bad condition was due to the high ambient temperature encountered by the larvae leading to insufficient food supply although the abundance of food at the end of the spawning season was relatively high. The simulations revealed that maximum survival of first-feeding cod larvae at high specific daily growth rates (because of high temperature) requires a prey density of $1200-1500$ nauplii $\cdot \mathrm{m}^{-3}$. The encountered food resembles the spatial and horizontal distribution of the implemented input prey fields: at the beginning of the spawning period relatively high amounts are available if $P$. elongatus is considered, whereas maximum nauplii abundance occurred during autumn without $P$. elongatus. The latter was due to potential drift routes to on average shallower waters. The drift within deeper waters as well as on average lower ambient temperature if $P$. elongatus was considered as prey is due to the higher number of surviving larvae dwelling at greater depth.

\section{Interannual variability}

We next simulated the interannual variability in survival and growth of larvae between 4.5 and $6 \mathrm{~mm}$ originating from peak spawning times of years 1986-1999 (Wieland et al. 2000). During the late 1980s, peak spawning took place between the beginning of May and mid-June. A remarkable shift in the timing of spawning to the end of July occurred in the 1990s. Model simulations were initialized by ignoring turbulence and using prey fields without $P$. elongatus (Figs. $4 a, 4 b$ ). The specified distribution and abundance of prey was mainly unfavourable for larval cod. This is reflected in low survival rates between 1 and $30 \%$ and a high number of starvation periods. Although the effect of the shift in spawning time is clearly visible in the ambient temperature, development time, nauplii abundance, and an increasing length-at-age, survival and starvation as well as weight were highly variable. It becomes obvious that the strong year-to-year variations do not depend on a single process but are influenced by a combination of different factors operating on different temporal and spatial scales (e.g., seasonality in temperature compared with transport into optimal feeding environment).

In the following we successively modified the simulations by $(i)$ the effect of turbulence on contact rates between predator and prey and (ii) taking into account the vertical distribution of the zooplankton prey within the layer $25-50 \mathrm{~m}$ deep. Survival derived from these analyses was generally higher, i.e., on average $9-17 \%$.

In simulations with both modifications, larval survival increased further to $\sim 20 \%$, whereas the days of starvation decreased. The unusually strong increase in survival in 1999 can be explained by the fact that larvae experienced unexpected low temperature for this period of the spawning season. Thus, for sustaining low growth rates, only low food supply was needed to enhance larval survival. In turn, larval weight at the end of the development was lower.

Finally, we incorporated the interannual trend in prey availability in the simulations. As no highly temporally and spatially resolving zooplankton abundance data were available, a time series (1986-1997) of prey availability to larval cod was constructed by multiplying mean nauplii abundance by its year-specific weights (Table 1) estimated from annual nauplii biomass estimates (Möllmann et al. 2000). These simulations, utilizing deviations from mean prey fields, have been performed for prey fields including P. elongatus. Additionally, the above-mentioned simplified vertical distribution of nauplii as well as turbulence-enhancing encounter rates between prey and predator have been included. These model runs illustrate optimal survival success until the beginning of the 1990s, whereas simulations for the most recent period resulted in relatively low survival rates (Fig. 5). The high survival success in the late 1980s and beginning of the 1990s was mainly due to low temperatures (low food requirement) and high nauplii abundance at the beginning of the spawning season. These simulations show clearly the effect of the long-term as well as the seasonal dynamics of P. elongatus on larval cod survival and growth. The decreasing stock of this copepod since the late 1980s, partly compensated for by a delay in cod peak spawning, resulted obviously in restricted food availability for first-feeding larvae. Relatively high survival success in 1996 was caused by highest wind speeds (Fig. 4b) registered during peak spawning periods in the covered time period and by low temperatures as well as relatively high food availability (Table 1). Although the surviving larvae seldom experienced starvation, their condition expressed by their weights at $6 \mathrm{~mm}$ was relatively low. Obviously, the minimum requirements for preventing starvation were met but resulted in poorly conditioned larvae. The increasing length after 70 days as a result of higher temperature reflects the shift in peak spawning time.

\section{Spatial variability}

The success of cod reproduction is dependent on certain minimum levels of salinity and oxygen concentration for egg fertilization and survival (>11 ppt, $2 \mathrm{~mL} \cdot \mathrm{L}^{-1}$, respectively) (e.g., Wieland et al. 1994; MacKenzie et al. 2000). These conditions are normally met only within the 60-m isobath. Retention and dispersion from the main spawning ground (Bornholm Basin) has been identified to be one of the key processes influencing recruitment success of the eastern Baltic cod stock (Voss et al. 1999; Hinrichsen et al. 2001). Thus, we analyzed the average spatial distribution of survival of first-feeding larvae in years 1986-1999 (Fig. 6). If prey fields without the copepod $P$. elongatus were considered, larvae initially released as Lagrangian drifters at the outer edge of the deep Bornholm Basin area had considerably higher survival rates $(20 \%)$, likely because of their lower drift distances towards the optimal feeding environments in more shallow coastal areas. In contrast, larvae hatching within the deep area of the Bornholm Basin during their firstfeeding stage required too much prey for survival along their onshore-oriented drift trajectories. A similar analysis performed for prey fields including $P$. elongatus revealed no areas within the deeper part of the Bornholm Basin leading to significant starvation mortalities (not shown). Only a small area within the Bornholm Deep shows slightly less than $100 \%$ survival probability.

\section{Validation of the biophysical model}

Physical properties simulated by the hydrodynamic model agree well with known circulation features and observed physical conditions in the Baltic (Lehmann and Hinrichsen 
Fig. 4. (a) Time series (1986-1999) of model output parameters of surviving larvae for peak spawning obtained from simulations without Pseudocalanus elongatus, without (solid bars) turbulence and including (shaded bars) turbulence and adjustment in zooplankton vertical distribution: survival rate, starvation periods, mean weight at $6 \mathrm{~mm}$ length, length after 70 days of drift and feeding, and development time. (b) Time series (1986-1999) of ambient environmental variables of surviving larvae obtained from simulations without P. elongatus, without (solid bars) turbulence and including (shaded bars) turbulence and adjustment in zooplankton vertical distribution: ambient temperature, bottom depth, larval depth, nauplii abundance, and wind speed.

a)
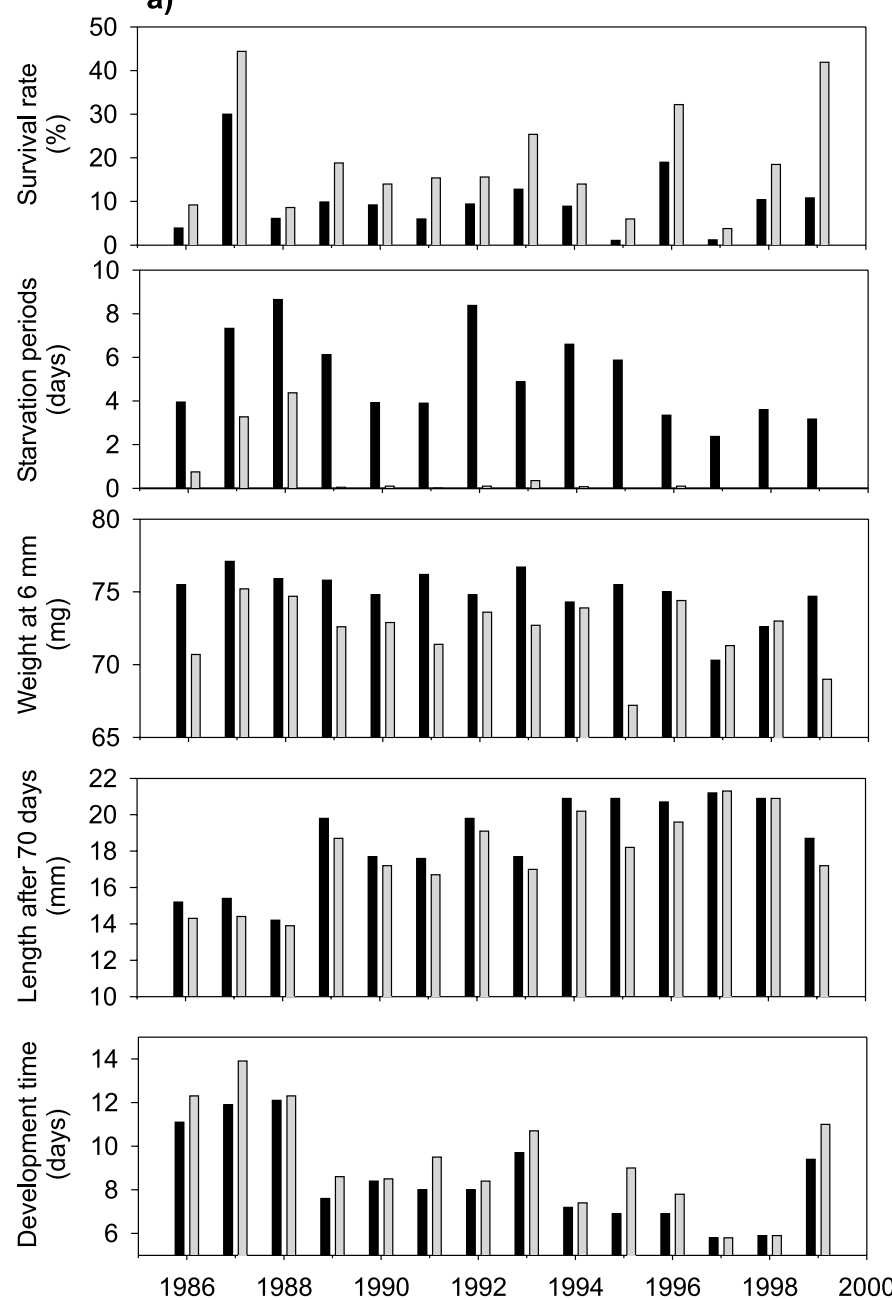

2000). Similarly, simulated mesoscale distribution patterns of larval cod were validated by field-based data (Voss et al. 1999). In contrast, because of the lack of suitable field-based larval data during the last decades (MacKenzie et al. 1996; STORE 2001), validating the biological component of the coupled model seems to be more critical. Thus, to assess the quantitative validity of the results, we tested their sensitivity to perturbations of the model input parameters. We provide the results of such a test (Table 2) corresponding to variations of the whole set of the submodel parameters for two time periods characterizing different survival rates of larval Baltic cod (September 1988 and July 1993).

Larval survival deviations derived by the performed sensitivity analyses (Table 2) indicate that linear relations between parameter perturbations and model predictions can be assigned to the foraging, growth, and starvation models, whereas encounter reacts nonlinearly to parameter variations. Here, search volume (or reactive distance) is an extremely important parameter, be- b)
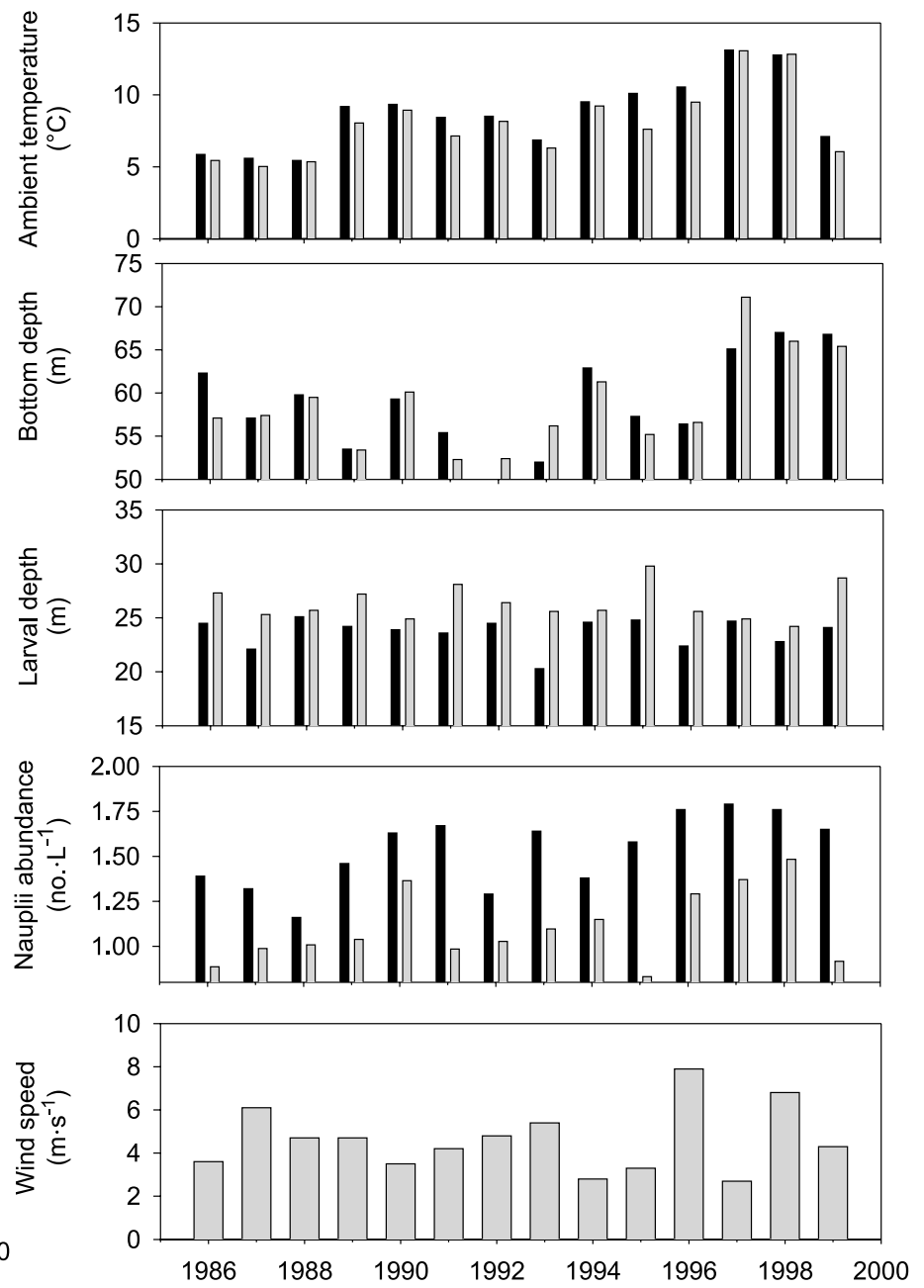

cause it is squared in the expression of the reactive area. Deviations resulting from variation of parameters in the growth and foraging model are insignificantly small. Larval survival was mainly altered by the variance of temperature and encounter, reflecting the strong influence of seasonal variations of atmospheric warming, prey availability, and the fraction of daylight hours. Similar effects were obtained as the result of variations in the larval search volume as well as the result of modification of the threshold value in the starvation model. Unfortunately, both parameters are difficult to observe in the field. At present, values have to be taken either from literature or from laboratory experiments, which necessarily might not resemble realistic conditions.

Comparing the ratio of observed recruitment and egg production at stage III of Baltic cod with the simulated larval survival potential by utilizing a simple linear regression model revealed a correlation coefficient of $r=0.78$, which is statistically highly significant $(P<0.02)$. The model was 
Fig. 5. Time series (1986-1997; 1992, no data) of model output parameters of surviving larvae for peak spawning obtained from simulations with weighted nauplii abundance including Pseudocalanus elongatus, turbulence, and adjustment in zooplankton vertical distribution: survival rates, starvation periods, mean weight at $6 \mathrm{~mm}$ length, and length after 70 days of drift and feeding.
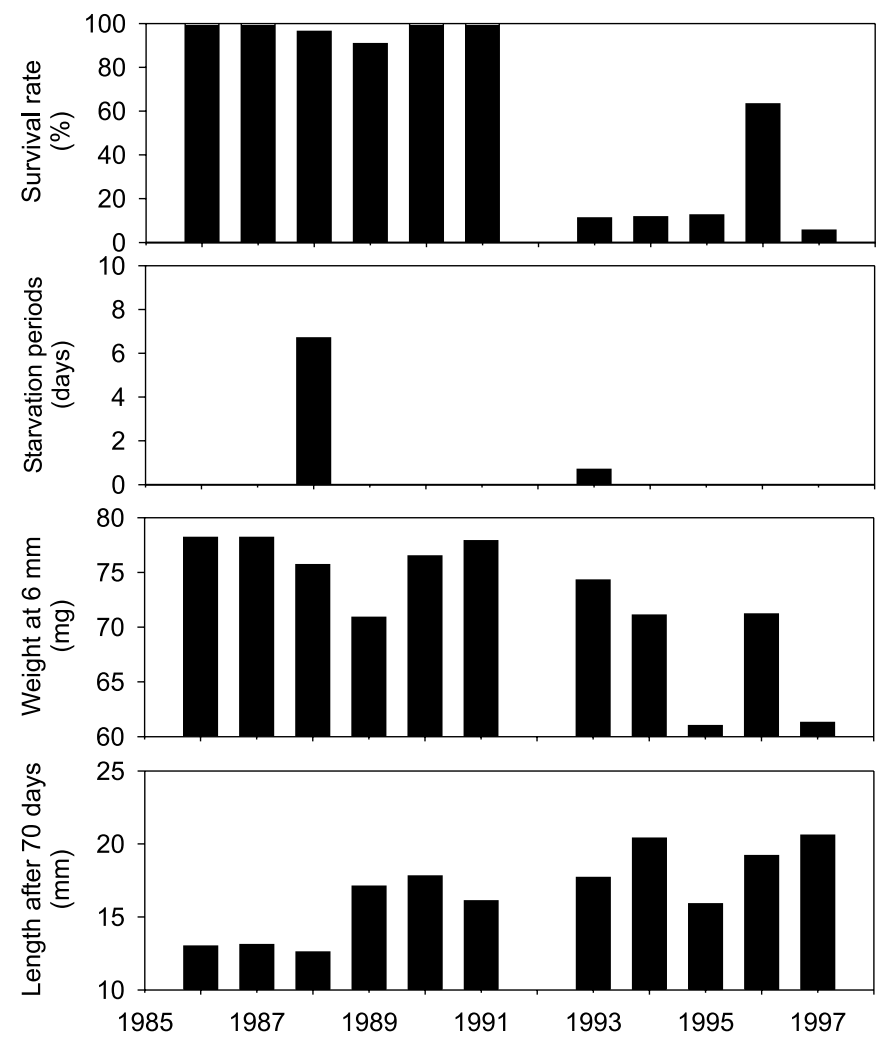

able to predict with a high degree of confidence relatively high levels of recruits and egg production from 1986 to 1991 as well as the strong decay of recruitment from 1993 onwards (Fig. 7).

The validity of the coupled biophysical model results have also been evaluated by simply relating recruitment success of Baltic cod to the availability of $P$. elongatus nauplii as prey. Both recruitment and availability of $P$. elongatus nauplii showed general declining trends towards the end of the 1990s, with extraordinarily high values at the end of the 1970s (Fig. 8). The correlation coefficient between both detrended time series was 0.6 . The reason for this relatively low association between recruitment and larval feeding potential is mainly as follows. Recruitment during the last decade depends on the production of late-hatched larvae as the main spawning season has successively changed from late spring to summer months (Wieland et al. 2000). Consequently, variability in the abundance of $P$. elongatus has had in this time period most likely only a limited impact on larval survival, depending to a higher extent on the availability of juvenile life stages of other copepod species. Excluding the late 1980s and 1990s from the correlation analysis increased the explained variance in Baltic cod recruitment residuals to about $60 \%$. Performing the same analysis for copepodite as well as for adult copepod stages results in weak relationships only, confirming that the phase from
Fig. 6. Average (1986-1999) horizontal distribution of mean larval survival probability in the Bornholm Basin obtained from simulations without Pseudocalanus elongatus and without turbulence.

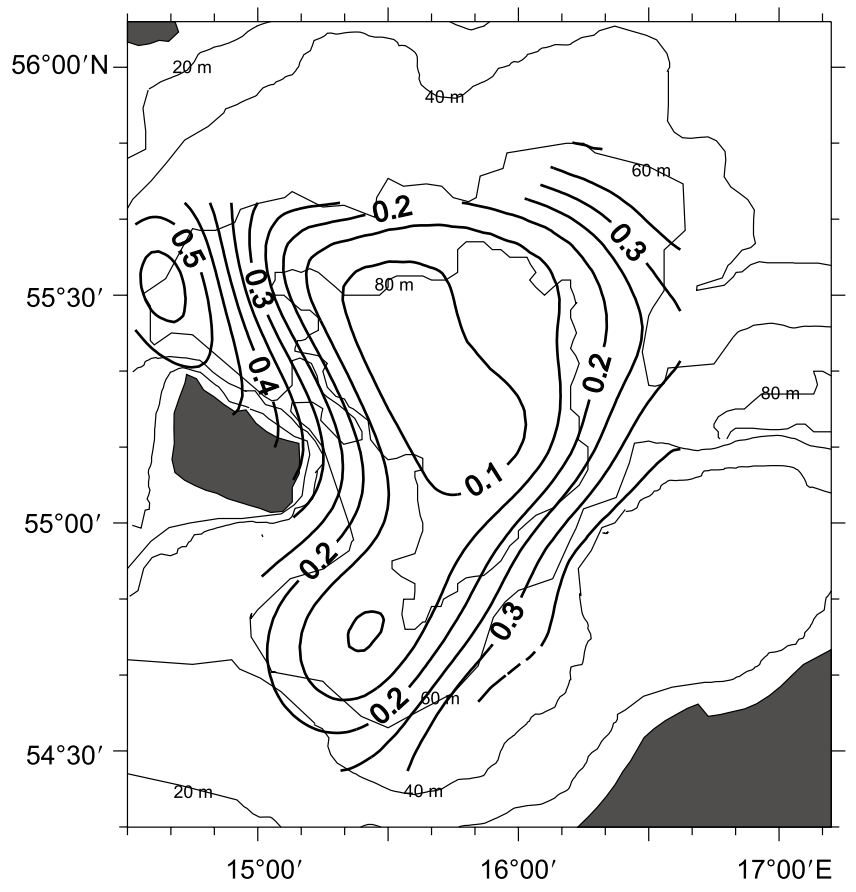

hatch to well-established feeder is the most critical early life stage of Baltic cod (Köster et al. 2001).

\section{Discussion}

Field studies on foraging behaviour of larval gadoids indicated the dependence of feeding success on the availability of nauplii of specific calanoid copepod species (e.g., Kendall et al. 1987). Thus, spatial and temporal variability in availability of this prey in combination with variation in ambient physical conditions, e.g., temperature and turbulence, might be responsible for intra- and inter-annual fluctuations in larval growth and survival. In turn, integrated measures of primary and secondary production in spawning and nursery areas are poor measures of the prey availability and are unlikely to aid in the prediction of fish recruitment (Campana et al. 1989). Because local biological and physical events may in fact explain counterintuitive early life stage growth and survival pattern, the development and utilization of coupled biophysical models became important for analyzing these combined effects on fish recruitment. These models considered the spatial heterogeneity in environmental conditions by integrating larval trophodynamic IBMs into threedimensional hydrodynamic models (Rose et al. 1993; Werner et al. 1993). As a research area presently of scientific interest, several of these coupled biophysical models have been established, e.g., for walleye pollock (Hermann et al. 1996, 2001; Hinckley et al. 1996), haddock off Scotland (Heath and Gallego 1998, 2000) and on Browns Bank (Brickman and Frank 2000; Brickman et al. 2001), bay anchovy from Chesapeake Bay (Rose et al. 1999), and cod on Georges Bank (Werner et al. 1996; Lynch et al. 2001).

In general, the hydrodynamic models using either Lagrangian particle tracking (e.g., Werner et al. 1993) or 
Table 2. Larval survival deviations (\%) derived from parameter perturbations for (a) 1988, Julian day 241, initial larval survival $73.3 \%$, and (b) 1993, Julian day 201, initial larval survival $11.2 \%$.

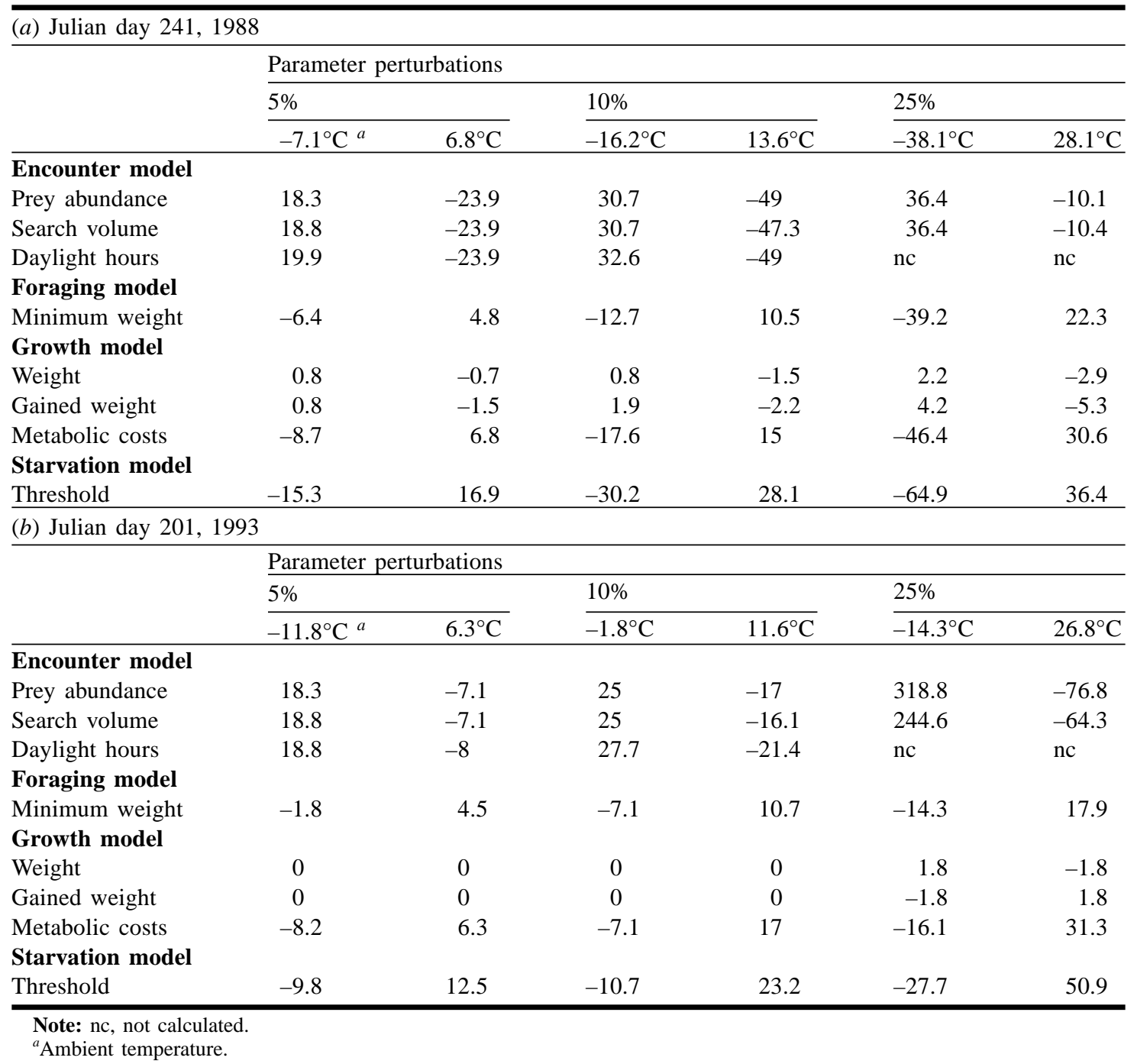

Fig. 7. Time series (1986-1997; 1992, no data) of recruitment (0 group) of Baltic cod, Gadus morhua (shifted to the year of origin), from virtual population analysis, in relation to egg production of Baltic cod at stage III (egg production III).

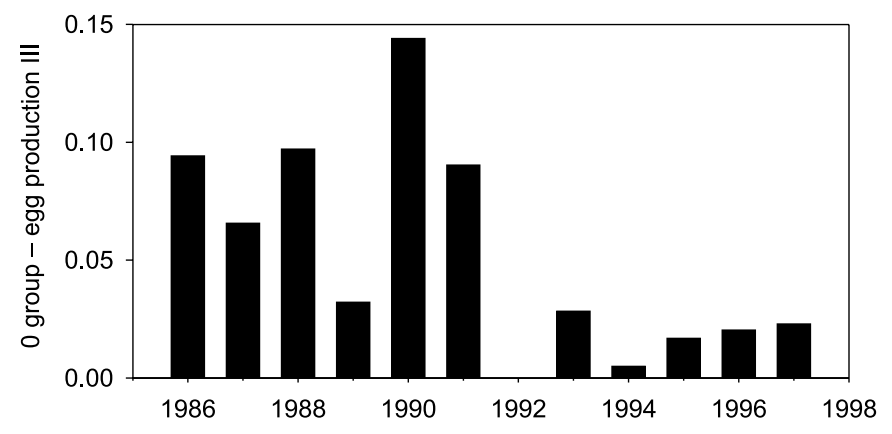

advection-diffusion equation models (Lynch et al. 1998) resolve the small-scale vertical and mesoscale horizontal hydrodynamics quite well. Because of the ephemeral nature of the atmospheric conditions over the Baltic Sea, in contrast to most previous studies, we considered it necessary to apply realistic atmospheric forcing conditions in our model runs. The resulting hydrodynamic features in the central Baltic are highly dynamic within the prolonged spawning period of cod.

The biological model components caused more problems in previous analyses, as well as in our present analysis, with larval growth, starvation, and related mortality being difficult to model, especially as prey fields are normally not available in sufficient temporal and spatial resolution. This general problem led in previous modeling approaches to the following assumptions: ( $i)$ prey concentration do not limit larval growth, making inclusion of prey-dependant feeding success and growth rates redundant (Heath and Gallego 1998); (ii) mean prey densities are uniform in space and time (e.g., Hermann et al. 1996); (iii) mean prey densities are variable over season, but invariant over years (Tyler et al. 1997), partly considering feedback by predation on prey density (Rose et al. 1999); (iv) mean prey densities vary horizontally as output of a quasi-static copepod population dynamic model (Lynch et al. 2001); or (v) mean prey densities are variable in space and time obtained from a three-dimensional nutrient- 
Fig. 8. Time series of recruitment of Baltic cod, Gadus morhua (shifted to the year of origin), from $(a)$ virtual population analysis and $(b)$ food availability (days.numbers $\cdot \mathrm{m}^{-3}$ ) of Pseudocalanus elongatus with corresponding long-term trends (solid lines).
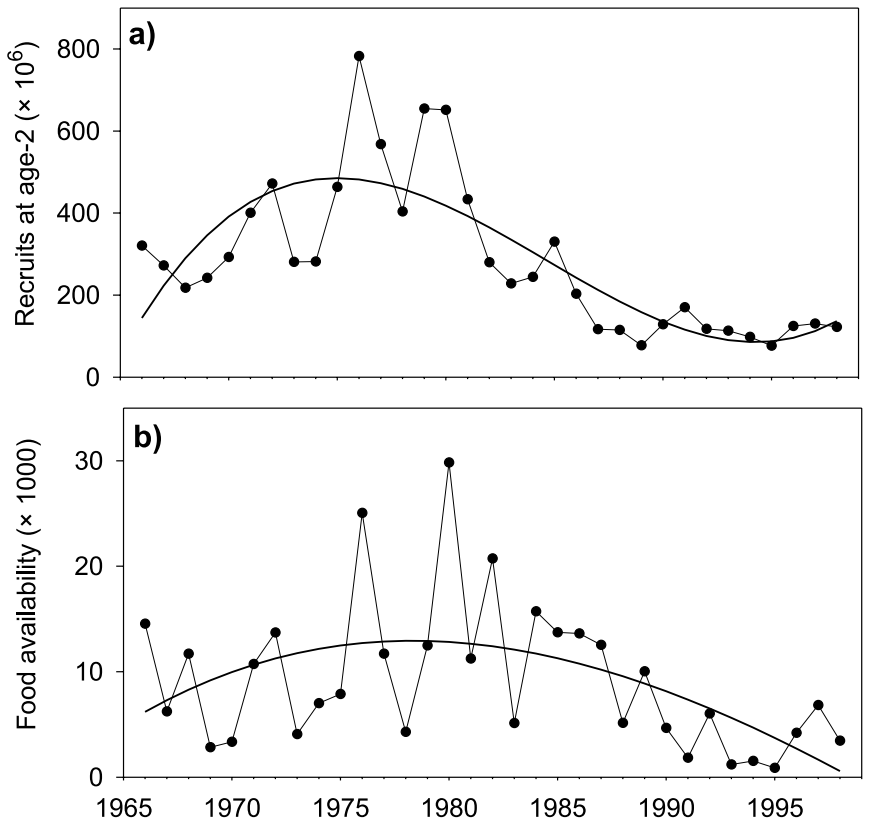

phytoplankton-zooplankton (NPZ) model (Hermann et al. 2001). Although we believe that the latter approaches are of great potential in future modeling activities, we considered it premature to couple copepod population models and more complex NPZ models for the Baltic Sea into our hydrodynamic model. Instead, our study is based on horizontally and seasonally variable prey densities in the depths of highest larval abundance obtained from extensive vertically and horizontally resolving zooplankton monitoring, applying overall yearly weighting factors to account for interannual variability in integrated prey abundance. We consider this parameterization as the best available description of the prey field for cod larvae in the central Baltic and as one of the first applications of a realistic prey field in a coupled trophodynamic-hydrodynamic model of larval survival.

The approach allowed us to re-address the question of food limitation in larval Baltic cod (for review, see MacKenzie et al. 1996), considering explicitly temporal and spatial variability in prey species-stage distribution and physical environmental conditions. For modeling the trophodynamics, we used only submodels developed and (or) parameters determined for cod larvae, although mainly stemming from other geographical locations. Exceptions are the assimilation efficiency, reactive distance, and starvation threshold taken from more generalized models (Breck and Gitter 1983; Letcher et al. 1996). The established coupled biophysical model is able to assess the overall influence of small-scale turbulence on encounter rates but does not consider that turbulence can have an overall detrimental effect on larval fish ingestion rate if exceeding a certain level depending also on larval behaviour (MacKenzie et al. 1994). This is justified by the fact that wind-induced turbulence in the central Baltic during cod spawning time in depths of larval occurrence does not reach intensities, which are expected to result in a decline in capture success (MacKenzie et al. 1996).

The primary aim of this study was to examine the influence of abiotic and biotic environmental variability on the potential larval survival success of Baltic cod. Generally, larval survival is strongly influenced by transport into favourable feeding environments and thus depends on hydrographic and meteorological forcing conditions. Although transport patterns of intermediate water layers where post-yolk-sac cod larvae mainly occur (Grønkjær and Wieland 1997) are relatively well known (Krauß and Brügge 1991; Voss et al. 1999; Hinrichsen et al. 2001), validation of the results of our coupled physical-biological modeling approaches is difficult. Several processes and factors are only partly resolved and thus parameterized in the model calculations. First, transport patterns of larvae are influenced by the initial spawning location assumed to be an even horizontal distribution, their initial vertical position in the water column and their behaviour. A diurnal vertical migration within the intermediate water layer, which varies with stage and size (Grønkjær and Wieland 1997), is especially not incorporated here. Secondly, trophodynamics are the most difficult processes to implement in models of larval growth and survival because of the difficulties in validating such models experimentally or by data obtained during field sampling. Besides the strong nonlinearity of trophodynamic relationships utilized, these relationships are often simplified to be computationally feasible. Finally, tests and validation of the IBM model results can only be performed for specific time periods and areas for which sufficient information on spatially resolved egg and (or) larval abundance, its prey, and physical forcing data are available, an exercise presently conducted for the spawning season 1999 (STORE 2001).

The present IBM approach has to cope with a relatively sparse temporal and spatial resolution of prey fields utilizing zooplankton data from the entire central Baltic. However, the sensitivity study demonstrated that the coupled biophysical model is sensitive enough to show the effects of parameter uncertainty and to demonstrate the impact of natural perturbation, especially in encounter and starvation processes. Other studies have suggested that biophysical models of larval growth and survival should additionally include light attenuation as well as irradiance (Fiksen et al. 1998). As demonstrated by Grønkjær and Wieland (1997), Baltic cod larvae concentrate in the water column just below the thermocline, where prey availability and light conditions during daytime are optimal for foraging. Cod larvae do not migrate vertically into surface water layers during night, although this would enhance light conditions for feeding (Grønkjær and Wieland 1997), most likely to avoid prevailing considerably higher temperatures. In consequence, feeding activity ceases during nighttime (Voss 2002). Although the latter process is included in our model formulation, we did not include variation in light intensity within a day or season, assuming cod larvae to adapt to changes in light intensity by optimizing their vertical position in the water column.

A process not incorporated in the model is predation on larval Baltic cod. Results from extensive literature and field investigations revealed clupeid fish (herring and sprat) to be important predators of cod early life history stages, mainly 
because of their high abundance in cod spawning areas during spawning times (Köster and Schnack 1994; Köster and Möllmann 1997). However, in contrast to cod eggs, larvae appear to be only marginally affected by clupeid predation, partly because of a spatial mismatch between predator and prey and partly because of a size selection favouring other prey (Köster and Möllmann 1997; Köster and Möllmann 2000). In future, planned IBM modeling approaches will incorporate the egg stage and consequently need to address the impact of predation on egg survival considering spatially resolved predator and prey fields.

We computed idealized prey fields by using a multiple nonlinear regression technique on existing zooplankton abundance data. This procedure yielded seasonal trends in abundance of copepod nauplii, which resemble the life-cycle patterns of the different species. The univoltine $P$. elongatus has an abundance maximum in April and May (Line 1979, 1984). In contrast, T. longicornis, Acartia spp., and C. hamatus having multiple generations (Line 1979, 1984) accumulate in June to produce next summer generations. Pseudocalanus elongatus nauplii in the central Baltic are associated with the vertical distribution of adults, preferring higher salinities (Dippner et al. 2000; Möllmann et al. 2000) encountered in deeper parts of the water column. This explains higher nauplii concentrations in the centre of the basin. Temora longicornis and Acartia spp., not confined to high salinities but to warmer waters (Dippner et al. 2000; Möllmann et al. 2000), were generally found in the upper $50 \mathrm{~m}$ of the water column and are distributed in more shallow regions. Nauplii of $C$. hamatus were observed mainly in the centre of the basin, which suggests a spawning in deeper layers similar to $P$. elongatus. However, the overall abundance of $C$. hamatus is low compared with other species. Although the constructed prey fields are considered to be realistic, simulating the decline in $P$. elongatus by excluding the abundance of this copepod in the low food environment scenario, underestimated the food abundance and thus probably also larval survival success.

Another parameter not well represented in our model approach is the size-specific selection of prey. Length-specific larval gut content data have been used to specify preferred prey organism according to species groups and stages for feeding larvae of different size classes. First-feeding larvae rely almost exclusively on copepod nauplii (Zuzarte et al. 1996), which we treated as one prey group, as size differences between species and stages are limited. Thus, our main results referring to first-feeding larvae are most likely not affected by a potential prey size selection process not considered in the model.

The model results suggest the necessity of the co-occurrence of peak prey and larval abundances and favourable oceanographic conditions for high survival rates. Also, inclusion of a more realistic description of the temporal and spatial distribution of the prey fields as well as prey aggregation influencing, e.g., the vertical distribution of larval fish, future modeling activities have to consider larval survival success with respect to mesoscale and small-scale horizontal patchiness of prey. Additionally, the intraannual evolution of zooplankton prey fields has to be validated by data obtained from specifically designed field campaigns (STORE 2001).
Our modeling results indicate central Baltic cod larvae $>6 \mathrm{~mm}$, feeding on all juvenile stages of copepods and later on adults and cladocerans, to be not food-limited. In contrast, first-feeding larvae (4.5-6 mm length) have changed from a nonlimited to a food-limited state, thus representing a critical early life history stage. This food limitation was caused by the decline in abundance of the copepod P. elongatus within the last two decades (Möllmann et al. 2000). Zooplankton distributions suggest prey concentrations to strongly vary in time and space independent of whether $P$. elongatus is considered or not. Including the abundance of this copepod, highest survival rates occurred during spring and early summer, whereas when neglecting P. elongatus, only late-hatched larvae, although less in magnitude, had higher chances to survive because of increasing abundances of other copepod nauplii. The shift in peak spawning time of Baltic cod (Wieland et al. 2000) obviously accounts for the decline in P. elongatus. Larvae are now born later in the season, thus profiting from the increasing abundances of juvenile stages of the remaining copepod species $T$. longicornis and Acartia spp. accumulating at this time of the year. It is not clear yet if spawning in general is delayed or if late spawners are the only surviving part of the eastern Baltic cod stock. The spatial analysis of the model output revealed that larvae in recent years had a high survival probability only when advected relatively fast to the margins of the $\mathrm{Ba}$ sin. This is due to the concentration of these copepods in more shallow areas.

In conclusion, our results show the dependence of Baltic cod larvae on climatic forcing conditions both directly in terms of transport and temperature and indirectly resulting from the impact on prey population development. In a recent study on the link between the North Atlantic Oscillation (NAO) and the Arctic sea-ice export, Hilmer and Jung (2000) found that the NAO underwent a secular change in the longitudinal position of the two pressure centres during the last two decades. The eastward movement of the centres of interannual NAO variability resulted in an increasing influence of the NAO on the Baltic Sea area, which was accompanied by a reduced flux of saline water masses into the deep basins of the Baltic Sea and an increased river runoff. A result of the decreasing salinity is the decay of the calanoid copepod $P$. elongatus during the last two decades (Möllmann et al. 2000). Our results showed that sufficient food to ensure high survival of Baltic cod larvae is strongly dependent on the occurrence of $P$. elongatus in the prey field. Thus, from this study it can be concluded that variations in prey availability on a climatic time scale might be considered as input parameters for recruitment predictions of fish stocks.

However, our modeling approach has not yet reached the state where the effects of zooplankton variability on early life stage survival can be assessed in a quantitative way, though it is to our knowledge one of the very few attempts to include realistic prey fields with spatial and temporal resolution into a biophysical model on larval survival. The modeling exercise has clearly demonstrated that traditional sampling methodology is unable to resolve food limitation of larvae without considering flow dynamics and the impact of physical conditions. It has demonstrated further that re- 
tention and dispersal of early life history stages can have detrimental as well as beneficial effects on offspring survival within a fish stock depending on seasonal specific prey availability.

\section{Acknowledgements}

The present study has been carried out with financial support from the Commission of the European Communities, Agriculture and Fisheries (FAIR) specific RTD programme CT983959, "Baltic STORE Project". It does not necessarily reflect the view of the Commission and in no way anticipates the Commission's future policy in this area. The authors wish to thank the anonymous referees who made several valuable comments and suggestions for improvement of the manuscript.

\section{References}

Bagge, O., Thurow, F., Steffensen, and Bay, E.J. 1994. The Baltic cod. Dana, 10: 1-28.

Bartell, S.M., Breck, J.E., Gardner, R.H., and Brenkert, A.L. 1986. Individual parameter perturbation and error analysis of fish bioenergetics models. Can. J. Fish. Aquat. Sci. 43: 160-168.

Blaxter, J.H.S. 1986. Development of sense organs and behaviour of teleost larvae with special reference to feeding and predator avoidance. Trans. Am. Fish. Soc. 115: 98-114.

Breck, J.E., and Gitter, M.J. 1983. Effect of fish size on the reactive distance on bluegill (Lepomis macrochirus) sunfish. Can. J. Fish. Aquat. Sci. 40: 162-167.

Brett, J.R. 1979. Environmental factors and growth. In Fish physiology. Vol. 8. Edited by W.S. Hoar, D.J. Randall, and J.R. Brett. Academic Press, London. pp. 599-675.

Brickman, D., and Frank, K.T. 2000. Modelling the dispersal and mortality of Browns Bank egg larval haddock (Melanogrammus aeglefinus). Can. J. Fish. Aquat. Sci. 57: 2519-2535.

Brickman, D., Shackell, N.K., and Frank, K.T. 2001. Modelling the retention and survival of Browns Bank haddock larvae using an early life stage model. Fish. Oceanogr. 10: 284-296.

Bryan, K. 1969. A numerical method for the study of the circulation of the world ocean. J. Phys. Oceanogr. 15: 1312-1324.

Buckley, L.J., and Dillmann, D.W. 1982. Nitrogen utilization by larval summer flounder Paralichthys dentatus (Linnaeus). J. Exp. Mar. Biol. Ecol. 59: 243-256.

Campana, S.E., Frank, K.T., Hurley, P.C.F., Koeller, P.A., Page, F.H., and Smith, P.C. 1989. Survival and abundance of young Atlantic cod (Gadus morhua) and haddock (Melanogrammus aeglefinus) as indicators of year class strength. Can. J. Fish. Aquat. Sci. 46: 171-182.

Cox, M.D. 1984. A primitive equation 3-dimensional model of the ocean. Geophysical Fluid Dynamics Laboratory (GFDL) Ocean Group Tech. Rep. No. 1, GFDL - Princeton University, Princeton, N.J.

Davis, C.S. 1984. Predatory control of copepod seasonal cycles on Georges Bank. Mar. Biol. 82: 31-40.

Dippner, J.W., Kornilovs, G., and Sidrevics, L. 2000. Long-term variability of meso-zooplankton in the central Baltic Sea. J. Mar. Syst. 25: 23-32.

Dower, J.F., Miller, T.J., and Leggett, W.G. 1997. The role of microscale turbulence in the feeding ecology of larval fishes. Adv. Mar. Biol. 31: 169-220.

Fennel, W. 1991. Rossby radii and phase speeds in the Baltic Sea. Cont. Shelf Res. 11: 23-36.
Fiksen, O., Utne, A.C.W., Aksnes, D.L., Eiane, K., Helvik, J.V., and Sundby, S. 1998. Modelling the influence of light, turbulence and ontogeny on ingestion rates in larval cod and herring. Fish. Oceanogr. 7: 355-363.

Fossum, P. 1986. A staging system of larval cod (Gadus morhua L.). Fiskeridir. Skr. Ser. Havunders. 18: 69-76.

Grønkjær, P., and Wieland, K. 1997. Ontogenetic and environmental effects on vertical distribution of cod larvae in the Bornholm Basin, Baltic Sea. Mar. Ecol. Prog. Ser. 154: 91-105.

Hänninen, J., Vuorinen, I., and Hjelt, P. 2000. Climatic factors in the Atlantic control the oceanographic and ecological changes in the Baltic Sea. Limnol. Oceanogr. 45: 703-710.

Heath, M., and Gallego, A. 1998. Bio-physical modelling of the early life stages of haddock, Melanogrammus aeglefinus, in the North Sea. Fish. Oceanogr. 7: 110-125.

Heath, M., and Gallego, A. 2000. Modelling the spatial and temporal structure of survivorship to settlement in North Sea and west of Scotland haddock. ICES CM 2000/N:11.

Hermann, A.J., Rugen, W.C., Stabeno, P.J., and Bond, N.C. 1996. Physical transport of young pollock larvae (Theragra chalcogramma) near Shelikof Strait. Fish. Oceanogr. 5: 58-70.

Hermann, A.J., Hinckley, S., Megrey, B.A., and Napp, J.M. 2001. Applied and theoretical considerations for constructing spatially explicit individual-based models of marine larval fish that include multiple trophic levels. ICES J. Mar. Sci. 58: 1030-1041.

Hernroth, L. 1985. Recommendation on methods for marine biological studies in the Baltic Sea, mesozooplankton biomass assessment. Baltic Marine Biologist, 10: 1-45.

Hilmer, M., and Jung, T. 2000. Evidence for a recent change in the link between the North Atlantic Oscillation and Arctic sea ice export. Geophys. Res. Lett. 27: 989-992.

Hinckley, S., Hermann, A.J., and Megrey, B.A. 1996. Development of a spatially explicit, individual-based model of marine fish early life history. Mar. Ecol. Prog. Ser. 139: 47-68.

Hinckley, S., Hermann, A.J., Meir, K.L., and Megrey, B.A. 2001. Importance of spawning location and timing to successful transport to nursery areas: a simulation study of Gulf of Alaska walleye pollock. ICES J. Mar. Sci. 58: 1042-1052.

Hinrichsen, H.-H., St. John, M., Aro, E., Grønkjær, P., and Voss, R. 2001. Testing the larval drift hypothesis in the Baltic Sea: retention vs. dispersion due to influence of wind driven circulation. ICES J. Mar. Sci. 58: 973-984.

Hinrichsen, H.-H., St. John, M., Lehmann, A., MacKenzie, B.R., and Köster, F.W. 2002. Resolving the impact of physical forcing variations on the eastern Baltic cod spawning environment. Journal of Marine Systems, 32: 281-294.

Houde, E.D. 1989. Subtleties and episodes in the early life of fishes. J. Fish Biol. 35(Suppl. A): 29-38.

Houde, E.D., and Zastrow, C.E. 1993. Ecosystem and taxon-specific dynamic and energetics properties of larval fish assemblages. Bull. Mar. Sci. 53: 290-335.

International Council on the Exploration of the Sea (ICES). 2001. Report of the Baltic Fisheries Assessment Working Group. ICES CM 2001/ACFM:18.

Kendall, A.W., Jr., Clarke, M.E., Yoklavich, M.M., and Boehlert, G.W. 1987. Distribution, feeding and growth of larval walleye pollock, Theragra chalcogramma, from Shelikof Strait, Gulf of Alaska. Fish. Bull. U.S. 85: 499-521.

Killworth, P.D., Stainforth, D., Webbs, D.J., and Paterson, S.M. 1991. The development of a free-surface Bryan-Cox-Semtner ocean model. J. Phys. Oceanogr. 21: 1333-1348.

Köster, F.W., and Möllmann, C. 1997. Predation by sprat and herring on early life stages of cod and sprat in the Central Baltic. 
Am. Fish. Soc. Lowell Wakefield Fisheries Symposium Series No. 14. pp. 41-69.

Köster, F.W., and Möllmann, C. 2000. Trophodynamic control by clupeid predators on recruitment success in Baltic cod. ICES J. Mar. Sci. 57: 310-323.

Köster, F.W., and Schnack, D. 1994. The role of predation on early life stages of cod in the Baltic. Dana, 10: 179-201.

Köster, F.W., Hinrichsen, H.-H., St. John, M.A., Schnack, D., MacKenzie, B.R., Tomkiewicz, J., and Plikshs, M. 2001. Developing Baltic cod recruitment models. II. Incorporation of environmental variability and species interaction. Can. J. Fish. Aquat. Sci. 58: $1534-1556$.

Krauß, W., and Brügge, B. 1991. Wind-produced water exchange between the deep basins of the Baltic Sea. J. Phys. Oceanogr. 11: 415-433.

Last, J.M. 1978. The food of three species of gadoid larvae in the eastern English Channel and southern North Sea. Mar. Biol. 48: 377-386.

Laurence, G.C. 1985. A report on the development of stochastic models of food limited growth and survival of cod and haddock larvae on Georges Bank. In Growth and survival of larval fishes in relation to the trophodynamics of Georges bank cod and haddock. Edited by G.C. Laurence and R.G. Lough. NOAA Tech. Mem. NMFS-F/NEC-36. pp. 83-150.

Lehmann, A. 1995. A three-dimensional baroclinic eddy-resolving model of the Baltic Sea. Tellus, 47A: 1013-1031.

Lehmann, A., and Hinrichsen, H.-H. 2000. On the thermohaline variability of the Baltic Sea. J. Mar. Syst. 25: 333-357.

Letcher, B.H., Rice, J.A., Crowder, L.B., and Rose, K.A. 1996. Variability in survival of larval fish: disentangling components with a generalized individual-based model. Can. J. Fish. Aquat. Sci. 53: 787-801.

Line, R.J. 1979. Some observations on fecundity and development cycles of the main zooplankton species in the Baltic Sea and the Gulf of Riga. In Fisheries investigations in the basins of the Baltic Sea. Vol. 14. Zvaigzne Publishers, Riga, Latvia. pp. 3-10. [In Russian.]

Line, R.J. 1984. On reproduction and mortality of zooplankton (Copepoda) in the south-eastern, eastern and north-eastern Baltic. In Articles on biological productivity of the Baltic Sea. Vol. 2. Moscow University, Moscow. pp. 265-274. [In Russian.]

Lynch, D.R., Gentleman, W.C, McGillicuddy, D.J., and Davis, C.S. 1998. Biological/physical simulations of Calanus finmarchicus population dynamics in the Gulf of Maine. Mar. Ecol. Prog. Ser. 169: $189-210$.

Lynch, D.R., Lewis, C.V.W., and Werner, F.E. 2001. Can Georges Bank larval cod survive on a calanoid diet? Deep-Sea Res. II, 48: 609-630.

MacKenzie, B.R., and Kiørboe, T. 1996. Encounter rates and swimming behavior of pause-travel and cruise larval fish predators in calm and turbulent laboratory environments. Limnol. Oceanogr. 40: $1278-1289$.

MacKenzie, B.R., Miller, T.J., Cyr, S., and Leggett, W.C. 1994. Evidence for a dome-shaped relationship between turbulence and larval fish ingestion rates. Limnol. Oceanogr. 39: 1790-1799.

MacKenzie, B.R., St. John, M.A., and Wieland, K. 1996. Eastern Baltic cod: perspectives from existing data on processes affecting growth and survival of eggs and larvae. Mar. Ecol. Prog. Ser. 134: 265-281.

MacKenzie, B.R., Hinrichsen, H.-H., Plikshs, M., Wieland, K., and Zezera, A.S. 2000. Quantifying environmental heterogeneity: habitat size necessary for successful development of cod Gadus morhua eggs in the Baltic Sea. Mar. Ecol. Prog. Ser. 193: 143-156.
Miller, T.J., Crowder, L.B., Rice, J.A., and Marshall, E.A. 1988. Larval size and recruitment mechanisms in fishes: toward a conceptual framework. Can. J. Fish. Aquat. Sci. 45: 1657-1670.

Möllmann, C., Kornilovs, G., and Sidrevics, L. 2000. Long-term dynamics of main zooplankton species in the central Baltic Sea. J. Plankton Res. 22: 2015-2038.

Morse, W.W. 1989. Catchability, growth and mortality of larval fishes. Fish. Bull. U.S. 87: 417-446.

Otterlei, E., Nyhammer, G., Folkvord, A., and Stefansson, S.O. 1999. Temperature- and size-dependent growth of larval and early juvenile Atlantic cod (Gadus morhua): a comparative study on Norwegian coastal cod and northeast Arctic cod. Can. J. Fish. Aquat. Sci. 56: 2099-2111.

Pepin, P., and Myers, R.A. 1991. Significance of egg and larval size to recruitment variability of temperate marine fish. Can. J. Fish. Aquat. Sci. 48: 1820-1828.

Press, W.H., Flannery, B.P., Teukolsky, S.A., and Fetterling, W.T. 1993. Numerical recipes in FORTRAN 77. The art of scientific computing. Cambridge University Press, New York. 848.

Rose, K.A., Christensen, S.W., and DeAngelis, D.L. 1993. Individual-based modelling of populations with high mortality: a new method based on following a fixed number of model individuals. Ecol. Model. 68: 273-292.

Rose, K.A., Cowan, J.H., Jr., Clark, M.E., Houde, E.D., and Wang, S.B. 1999. An individual-based model of bay anchovy population dynamics in the mesohaline region of Chesapeake Bay. Mar. Ecol. Prog. Ser. 185: 113-132.

Rothschild, B.J. 2000. Fish stocks and recruitment: the past thirty years. ICES J. Mar. Sci. 57: 191-201.

Rothschild, B.J., and Osborn, T.R. 1988. Small-scale turbulence and plankton contact rates. J. Plankton Res. 10: 465-474.

Semtner, A.J. 1974. A general circulation model for the World Ocean. UCLA Department of Meteorology Tech. Rep. No. 8.

STORE (Stock Recruitment). 2001. Environmental and fisheries influences on fish stock recruitment in the Baltic. Consolidated Progress Report. EU-Project FAIR CT 983959 (www.ifm.unikiel.de/fb/fb3/fi/research/projects/STORE/welcome.htm).

Tyler, J.A., Rose, K.A., and Chambers, C. 1997. Compensatory responses to decreased young-of-the-year survival: an individualbased modelling analysis of winter flounder. In Early life history and recruitment in fish populations. Edited by R.C. Chambers and E.A. Trippel. Chapman and Hall Fish and Fisheries Series, London. pp. 391-422.

UNESCO (United Nations Educational, Scientific and Cultural Organization) Press. 1968. Zooplankton sampling. Monogr. Oceanogr. Methodol. 2.

Voss, R. 2002. Recruitment processes in the larval phase: the influence of varying transport on cod and sprat larval survival. Ph.D. thesis, University of Kiel, Kiel, Germany.

Voss, R., Hinrichsen, H.-H., and St. John, M. 1999. Variations in the drift of larval cod (Gadus morhua L.) in the Baltic Sea: combining field observations and modelling. Fish. Oceanogr. 8(3): 199-211.

Werner, F.E., Page, F.H., Lynch, D.R., Loder, J.W., Lough, R.G., Perry, R.I., Greenberg, D.A., and Sinclair, M.M. 1993. Influences of mean advection and simple behavior on the distribution of cod and haddock early life stages on Georges Bank. Fish. Oceanogr. 2: 43-64.

Werner, F.E., Perry, R.I., Lough, R.G., and Naimie, C.E. 1996. Trophodynamic and advective influences on Georges Bank larval cod and haddock. Deep-Sea Res. II, 43: 1793-1822.

Wiborg, K.F. 1948. Investigations on cod larvae in the coastal waters of northern Norway. Fiskeridir. Skr. Ser. Havunders. 9: 1-27. 
Wieland, K. 1995. Einfluss der Hydrographie auf die Vertikalverteilung und Sterblichkeit der Eier des Ostseedorsches (Gadus morhua callarias) im Bornholm Becken, südliche zentrale Ostsee. Berichte ans dem Institut für Meereskunde Kiel 266.

Wieland, K., Waller, U., and Schnack, D. 1994. Development of Baltic cod eggs at different levels of temperature and oxygen content. Dana, 10: 163-177.
Wieland, K., Jarre-Teichmann, A., and Horbowa, K. 2000. Changes in the timing of spawning of Baltic cod: possible causes and implications for recruitment. ICES J. Mar. Sci. 57(2): 452-464.

Zuzarte, F., Köster, F.W., Möllmann, C., Voss, R., and Grønkjær, P. 1996. Diet composition of cod larvae in the Bornholm Basin. ICES CM 1996/J:19. 